\title{
The COVID-19 post-pandemic scenario to Oral Radiology at Dental Schools
}

\author{
Beatriz S. P. A. Rosa ${ }^{1} \cdot$ Matheus Diniz Ferreira ${ }^{2}$ ( Gabrielle C. Moreira ${ }^{3} \cdot$ Mayara F. Bastos $^{1} \cdot$ Rafael R. Pinto $^{1}$. \\ Maria Augusta Visconti ${ }^{1} \cdot$ Rafael B. Junqueira $^{3} \cdot$ Francielle S. Verner $^{3}$
}

Received: 9 June 2020 / Accepted: 10 July 2020 / Published online: 18 July 2020

(c) Japanese Society for Oral and Maxillofacial Radiology and Springer Nature Singapore Pte Ltd. 2020

The coronavirus disease 2019 (COVID-19) pandemic has infected almost 8 million people, with more than 525,000 deaths, as the July 04th, 2020 (https://coronavirus.jhu.edu/ map.html). Many countries over the world are rolling out a phased approach to reopening, and according to a recent study [1] it should be based on analyzing the risk, prevention and managing the problem. Thus, it is essential to concern with a return strategy for Dental Schools, to identify and reduce the risks and to prevent cross contamination, contributing to COVID-19 spread control.

Oral Radiology teaching includes theoretical and practical classes with image interpretations and radiographic technique performance [2]. For the post-pandemic scenario, theoretical activities can be performed remotely [2]. Furthermore, e-learning may be as effective as traditional classroom methods in students' knowledge gain and performance on clinical procedures in Oral Radiology [3]. It is important to emphasize that e-learning avoids unnecessary crowding of people and associated risk of infection. Still, the radiographic techniques classes can only be performed personally, and updated infection control procedures are urgently necessary.

The practical classes of Oral Radiology at Dental Schools are quite different from the daily routine at private clinics, with many students sharing the same spaces, and several patients being assisted simultaneously. Once the main

Matheus Diniz Ferreira

mdiniz332@hotmail.com

1 Department of Pathology and Oral Diagnosis, School of Dentistry, Federal University of Rio de Janeiro (UFRJ), Rio de Janeiro, Brazil

2 Department of Oral Diagnosis, Piracicaba Dental School, University of Campinas (FOP-UNICAMP), Avenida Limeira, 901, Areião, Piracicaba, São Paulo 13414-903, Brazil

3 Department of Dentistry, Federal University of Juiz de Fora, Campus GV (UFJF-GV), Governador Valadares, Brazil objective in these institutions is teaching, the service time is longer due to the student's learning process. Thus, it is challenging to Dental Schools to adopt a strict protocol that, at the same time, speeds up the service, increases biosafety and ensures learning. It is important to balance social distancing to slow COVID-19 spread, while still maintaining the workforce needed to provide clinical patient care.

Intraoral radiographs are the most used imaging exams in Dentistry, and they are the radiographic techniques that offer greater contamination risk between patients and professionals [4]. Thus, extraoral imaging, such as panoramic radiography and cone-beam computed tomography, could be viable alternatives during the outbreak of COVID-19 [5]. However, periapical radiographies are indispensable in several clinical situations or even are the only imaging exams available, e.g. at some Public Dental Schools in Brazil. Moreover, the current reality in many of such clinics is not to have enough digital radiographic equipment, increasing the risk of contamination, through imaging processing and handling.

In the face of the post-pandemic scenario, in addition to the recently updated biosafety guidelines for dental care [6], we would like to highlight some specific recommendations and readjustments for Oral Radiology Departments at Dental Schools. Imaging receptors should be double barriered to prevent perforation and cross contamination [5]. The implementation of a fully digital system is imperative, which can minimize the risks of document-mediated transmission from infected individuals [7]. In addition, the development of institutional digital platforms to provide imaging transfer, remote diagnosis, results checking, and clinical cases discussion by the students may play an important role.

We hope that the COVID-19 pandemic will be an incentive for the modernization of Dental Schools globally, ensuring effective education of Oral Radiology with benefits to patient care. 


\section{Compliance with ethical standards}

Conflict of interest Authors Beatriz S. P. A. Rosa, Matheus D. Ferreira, Gabrielle C. Moreira, Mayara F. Bastos, Rafael R. Pinto, Maria Augusta Visconti, Rafael B. Junqueira e Francielle S. Verner declare that they have no conflict of interest.

Human and animal rights This article does not contain any studies with human or animal subjects performed by the any of the authors.

\section{References}

1. Miller CS, Carlson CR. A blueprint for recovery for the postcoronavirus (COVID-19) World. Oral Dis. 2020. https://doi. org/10.1111/odi.13407.10.1111/odi.13407.

2. Pontual MLA, do Nascimento EHL, da Cruz Perez DE, Pontual AA, Ramos-Perez FM. Challenges in Oral Radiology teaching during COVID-19 pandemic. Dentomaxillofac Radiol 2020;14:20200178. https://doi.org/10.1259/dmfr.20200178

3. Santos GNM, Leite AF, Figueiredo PTS, Pimentel NM, Flores-Mir C, Melo NS, et al. Effectiveness of E-Learning in oral radiology education: a systematic review. J Dent Educ. 2016;80:1126-39.
4. da Costa ED, da Costa AD, Lima CAS, Possobon RF, Ambrosano GMB. The assessment of adherence to infection control in oral radiology using newly developed and validated questionnaire (QICOR). Dentomaxillofac Radiol. 2018;47:20170437. https:// doi.org/10.1259/dmfr.20170437.

5. Ather A, Patel B, Ruparel NB, Diogenes A, Hargreaves KM. Coronavirus Disease 19 (COVID-19): implications for clinical dental care. J Endod. 2020;46:584-95. https://doi.org/10.1016/j. joen.2020.03.008.

6. Centers for Disease Control and Prevention (2020) CDC guidance for providing dental care during COVID-19. https://www.cdc.gov/ oralhealth/infectioncontrol/statement-COVID.html. Accessed 20 May 2020

7. Yu J, Ding N, Chen H, Liu XJ, He WJ, Dai WC, et al. Infection control against COVID-19 in Departments of Radiology. Acad Radiol. 2020;27(5):614-7. https://doi.org/10.1016/j. acra.2020.03.025.

Publisher's Note Springer Nature remains neutral with regard to jurisdictional claims in published maps and institutional affiliations. 